\title{
Effects of Anemia and Uremia and a Combination of Both on Cardiovascular Structures
}

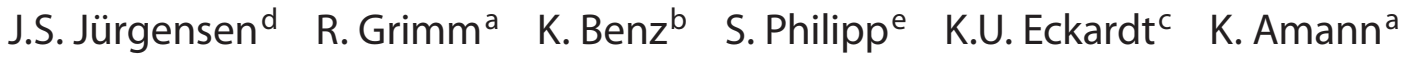 \\ Departments of a Pathology, ${ }^{b}$ Pediatrics, and ${ }^{\mathrm{C}}$ Nephrology and Hypertension, University of Erlangen-Nürnberg, \\ Erlangen, dDepartment of Internal Medicine, Charité, Campus Virchow Clinic, Berlin, and \\ eDepartment of Cardiology, West-German Heart Center Essen, Essen, Germany
}

\section{Key Words}

Anemia $\cdot$ Uremia $\cdot$ Heart $\cdot$ Capillaries $\cdot$ Fibrosis $\cdot$ Aorta

\begin{abstract}
Background: Cardiovascular complications are a major cause of morbidity and mortality in chronic renal failure (CRF) patients. Chronic anemia is a complication of CRF and a cardiovascular risk factor per se. It was the aim of the present study to clarify whether uremia and anemia are additive or supra-additive with respect to cardiovascular alterations. Methods: Thirty SD rats were sham operated (sham) or subtotally nephrectomized (SNX). Both groups were subdivided into anemic (target hemoglobin $10 \mathrm{~g} / \mathrm{dl}$, by tail artery punctures) and untreated animals. Blood pressure, echocardiographic measurements and morphometric investigations were performed. The study was terminated after 16 weeks. Results: Heart rate and blood pressure were similar in all groups. Anemia was comparable in sham+anemia and SNX+anemia. Left ventricular end-diastolic pressure was significantly higher in untreated SNX and SNX+anemia than in sham. Anemia and SNX caused comparable left ventricular hypertrophy (LVH), which was significantly higher in
\end{abstract}

SNX+anemia. In sham animals, anemia induced thickening of intramyocardial arteries, which was significantly more pronounced in SNX with no additional effect of anemia. Conclusions: Experimentally, anemia and CRF induced LVH and intramyocardial arteriolar thickening. If both are combined, the increase in LVH is even more marked, whereas there are no additional effects on intramyocardial structural alterations.

Copyright $\odot 2010$ S. Karger AG, Basel

\section{Introduction}

Anemia is a well-known regular feature of chronic renal failure (CRF) and has been documented to be an important cardiovascular risk factor in CRF both in experimental and in clinical studies. Recently, the joint occurrence of cardiovascular disease, kidney disease and anemia has been termed the 'cardio-renal anemia syndrome' $[1,2]$. Since recombinant human erythropoietin became available, anemia has been increasingly recognized as an adverse risk factor for patient morbidity and mortality. In several large patient populations with CRF,

\section{KARGER}

Fax +4161306 1234 E-Mail karger@karger.ch www.karger.com
(C) 2010 S. Karger AG, Basel

$1420-4096 / 10 / 0334-0274 \$ 26.00 / 0$

Accessible online at:

www.karger.com/kbr
Kerstin Amann, MD

Department of Pathology, University of Erlangen-Nürnberg

Krankenhausstrasse 8-10, DE-91054 Erlangen (Germany)

Tel. +49 9131852 2291, Fax +49 91318522601

E-Mail kerstin.amann@uk-erlangen.de 
an inverse relationship has been observed between hemoglobin $(\mathrm{Hb})$ levels and mortality risk, which extends into the normal range of $\mathrm{Hb}$ values [3, 4]. Meanwhile, an association between the presence of a reduced $\mathrm{Hb}$ concentration and outcome has also been recognized in nonrenal patient populations, such as patients with heart failure [5], as well as in apparently healthy individuals [6].

Whether this relationship between reduced $\mathrm{Hb}$ levels and adverse prognosis reflects causality is less clear. Under anemic conditions, blood oxygen carrying capacity is reduced, but unless the degree of anemia is very severe, total body oxygen consumption is maintained constant [7]. This is due to two main compensatory responses: (a) an increase in cardiac output and (b) increased oxygen extraction from $\mathrm{Hb}$ molecules, which will also reduce tissue oxygen tensions. Both mechanisms could theoretically affect organ structure and function. In fact, a chronic increase in cardiac output is considered a potential mechanism that contributes to the development of left ventricular hypertrophy (LVH) through volume overload. The incidence of LVH increases progressively with declining renal function and is greater than $70 \%$ in patients entering dialysis [8]. In patients with severe renal anemia, partial correction of $\mathrm{Hb}$ levels was found to reduce $\mathrm{LVH}$, suggesting that anemia is an important contributor to the pathogenesis of LVH in CRF patients [9]. However, more recent studies comparing different target $\mathrm{Hb}$ values in CRF patients before dialysis and after beginning dialysis therapy failed to demonstrate a positive effect of higher target levels on left ventricular geometry, and there is even some evidence for a negative effect of high $\mathrm{Hb}$ on cardiovascular mortality [4].

Importantly, marked changes in cardiac histomorphology accompany LVH in experimental renal failure as well as in patients with CRF. In addition to hypertrophy of cardiomyocytes, these changes include cardiac interstitial fibrosis, arteriolar wall thickening as a result of both hypertrophy and hyperplasia of vascular cells [10, 11] and finally a marked capillary deficit [12] resulting from a mismatch between cardiomyocyte hypertrophy and capillary growth, respectively. This capillary deficit is much more marked than in other conditions of $\mathrm{LVH}$, i.e. essential or renovascular hypertension [13]. It is possible that this reduction in capillary density renders the myocardium more susceptible to reductions in oxygen carrying capacity. However, in the clinical situation, the specific role of anemia is difficult to decipher and to separate from other effects of CRF. We therefore decided to use an experimental model to investigate the effects of anemia separately and in combination with renal insufficiency induced by 5/6 nephrectomy of the rat [14]. Our results indicate that anemia alone can induce marked changes in cardiac structure and function and has the potential to aggravate the cardiac pathology that accompanies CRF.

\section{Material and Methods}

\section{Animals}

Thirty male 200 g Sprague-Dawley rats were housed at constant room temperature $\left(20^{\circ} \mathrm{C}\right)$ and humidity under a controlled light-dark cycle. The rats had free access to standard chow and tap water. After a 3-day adaptation period, the animals were randomly allotted to sham-operated control groups (sham), i.e. (1) untreated (sham) and (2) phlebotomies (sham+anemia), and subtotally nephrectomized groups (SNX), i.e. (3) untreated (SNX) and (4) phlebotomies (SNX+anemia).

Groups 1 and 2 were sham-operated, whereas groups 3 and 4 underwent standardized two-step subtotal surgical nephrectomy. In a first operation, the right kidney was removed under general anesthesia (ketamine, xylazine) and weighed. Sham operation consisted in decapsulation of the kidney taking special care not to damage the adrenals. After 1 week, subtotal nephrectomy was completed by resection of the lower and upper poles of the left kidney. In order to standardize the procedure, an amount of cortex corresponding to $66 \%$ of the weight of the removed right kidney was resected [15]. Sham operation was performed as described above. This standardized procedure of a two-step, weightcontrolled surgical resection of renal cortex resulted in a very moderate and stable degree of renal failure with no or only minor increase in systolic blood pressure. Using the above-described procedure of moderate two-step subtotal nephrectomy, the total nephron number is reduced from approximately 60,000 to 15,000 .

Of note, induction of chronic anemia in the rat is difficult, and we decided to use the technique of repetitive phlebotomy. Fortyeight hours after the second operation, induction of anemia was started by puncture of the tail artery. After local warming of the tail, up to $25 \%$ of the calculated circulating blood volumes were removed up to three times per week in order to achieve the target hematocrit of $30 \%$ [16]. Individual determination of frequency and target volume were based on the hematocrit level of the previous sample for each animal to assure a rather constant degree of anemia.

A substantial initial overhead in the number of animals accounted for the expectedly high dropout rate in the treatment groups. Finally, 4 animals per group were followed for the whole period of 16 weeks except for the subtotally nephrectomized group with induced anemia where only 3 animals remained. The investigation conformed to the guide for the care and use of laboratory animals published by the US National Institutes of Health and was approved by the local ethics committee. 


\section{Echocardiography}

A two-dimensional short-axis and long-axis view of the left ventricle was obtained with a $15-\mathrm{MHz}$ phased array transducer (Acuson Sequoia, Erlangen, Germany) in anesthetized rats. Three M-mode tracings per heart were recorded and averaged to determine the diameter of the left ventricle at the end of the diastole and systole. Ejection fraction was calculated using short- and long-axis views. Measurements were done by an observer blinded to treatment according to the American Society for Echocardiography leading edge method.

\section{Measurement of Blood Pressure and Left Ventricular}

End-Diastolic Pressure

After 16 weeks, rats were intubated and artificially ventilated under chloral hydrate anesthesia. A PE 50 catheter was inserted through the right jugular vein into the superior vena cava. Arterial blood pressure was measured directly via the left carotid artery, and left ventricular end-diastolic pressure (LVEDP) was obtained with a Millar tip high-fidelity catheter and registered with a Statham transducer (P23XL) and a Gould amplifier (AMP 4600) as previously described [17].

\section{Tissue Preparation}

After the above-mentioned recordings and blood sampling, the experiment was terminated by retrograde perfusion fixation via the abdominal aorta. After perfusion, the heart of each animal was taken out, and the total heart weight as well as the left ventricular weight were determined. Tissue samples and sections were obtained and stained according to the orientator method [15, 18]. Briefly, uniformly random sampling of the myocardium was achieved by preparing a set of equidistant slices of the left ventricle and the interventricular septum with a random start. Two slices were selected by area-weighted sampling and processed accordingly. Eight pieces of the left ventricular muscle including the septum were prepared and afterwards embedded in EponAraldite. Semi-thin sections $(0.8 \mu \mathrm{m})$ were stained with methylene blue and basic fuchsin and examined by light microscopy with oil immersion and phase contrast at a magnification of $\times 1,000$.

All investigations were performed in a blinded manner, i.e. the observer was unaware of the study group the animal belonged to. Stereological analysis was performed on eight random samples of differently orientated sections of the left ventricular myocardium per animal according to the orientator method [15]. Volume density $\left(\mathrm{V}_{\mathrm{V}}\right)$ of capillaries, interstitial tissue and myocytes was obtained using the point counting method according to the equation $\mathrm{P}_{\mathrm{P}}=\mathrm{V}_{\mathrm{V}}$ (where $\mathrm{P}_{\mathrm{P}}$ is point density). Using the point counting method and a magnification of $\times 1,000$, these structures can be easily identified and counted on semi-thin sections using standard criteria. Reference volume was the total myocardial tissue (exclusive of noncapillary vessels, i.e. arterioles and veins, and tissue clefts). Vascular geometry of intramyocardial arterioles, i.e. vessels with lumen diameters between 20 and 120 $\mu \mathrm{m}$ and at least one muscular layer, was analyzed using planimetry and a semiautomatic image analysis system (Analysis, SIS, Münster, Germany), as described in detail [15]. Thereby, mean wall thickness, lumen diameter, media and lumen area were determined in every arteriole that was present in the 8 semi-thin sections per animal.

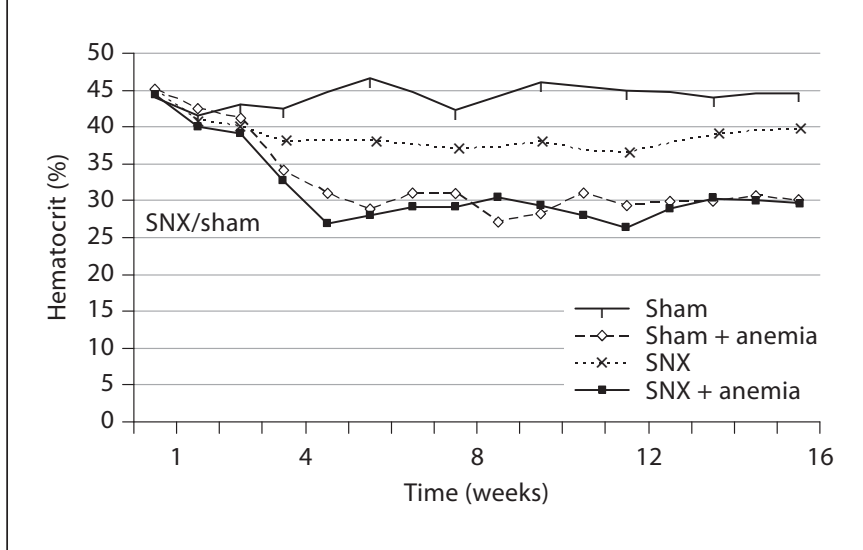

Fig. 1. Time course of the hematocrit. Changes of the hematocrit during the 16 week-study period are depicted for the four groups. Arrowheads mark the surgical interventions (SNX or sham) at the start of the investigation.

\section{Statistics}

Statistical analysis was performed with SPSS 13. Data are given as mean \pm standard deviation. ANOVA was used for comparison of means followed by appropriate post-hoc tests. Levene's test was used to assess the equality of variances. If distributional assumptions were in doubt, the nonparametric Kruskal-Wallis test was chosen. The zero hypothesis was rejected at $\mathrm{p}<0.05$.

\section{Results}

\section{Animal Data}

Serum Parameters, Body Weight and Hematocrit

Course

S-creatinine was significantly higher in both SNX, with no difference between untreated and anemic animals. As expected, hematocrit was significantly lower in both anemic groups than in sham and untreated SNX. In addition, hematocrit was significantly lower in untreated SNX than in untreated sham (fig. 1). Body weight at the end of the experiment was highest in untreated sham and significantly lower in the other three groups. Heart weight (perfused heart) was significantly higher in SNX+anemia than in untreated SNX. Relative left ventricular weight, i.e. left ventricular weight per body weight ratio, was lowest in untreated sham and significantly higher in the other three groups; it was highest in SNX+anemia, and the difference between this group and sham+anemia and untreated SNX was statistically highly significant, indicat- 
Table 1. Animal data

\begin{tabular}{|c|c|c|c|c|c|c|c|}
\hline Group & $\begin{array}{l}\text { Body } \\
\text { weight, g }\end{array}$ & $\begin{array}{l}\text { Heart } \\
\text { weight, g }\end{array}$ & $\begin{array}{l}\text { Relative left ventricu- } \\
\text { lar weight, mg/g b.w. }\end{array}$ & $\begin{array}{l}\text { S-creatinine } \\
\mathrm{mg} / \mathrm{dl}\end{array}$ & $\begin{array}{l}\text { Hematocrit } \\
\%\end{array}$ & $\begin{array}{l}\text { Systolic blood } \\
\text { pressure, } \mathrm{mm} \mathrm{Hg}\end{array}$ & $\begin{array}{l}\text { LVEDP } \\
\mathrm{mm} \mathrm{Hg}\end{array}$ \\
\hline Untreated sham $(\mathrm{n}=4)$ & $464 \pm 11.3$ & $1.901 \pm 0.11$ & $2.47 \pm 0.074$ & $0.59 \pm 0.11$ & $44.5 \pm 1.29$ & $111 \pm 4.32$ & $5.40 \pm 1.40$ \\
\hline Sham+anemia $(\mathrm{n}=4)$ & $394 \pm 28.0^{\mathrm{a}}$ & $1.822 \pm 0.169$ & $2.76 \pm 0.13^{\mathrm{a}, \mathrm{b}}$ & $0.44 \pm 0.07$ & $30.0 \pm 2.16^{\mathrm{a}, \mathrm{c}}$ & $117 \pm 3.11$ & $9.48 \pm 4.64$ \\
\hline Untreated SNX $(\mathrm{n}=4)$ & $399 \pm 9.6^{\mathrm{a}}$ & $1.736 \pm 0.122^{\mathrm{b}}$ & $2.92 \pm 0.12^{\mathrm{a}, \mathrm{b}}$ & $1.94 \pm 0.69^{\mathrm{a}, \mathrm{d}}$ & $39.0 \pm 2.94^{\mathrm{a}, \mathrm{b}}$ & $118 \pm 18.6$ & $22.0 \pm 12.2^{\mathrm{a}}$ \\
\hline SNX+anemia $(n=3)$ & $377 \pm 25.9^{\mathrm{a}}$ & $2.086 \pm 0.128^{c}$ & $3.32 \pm 0.17^{\mathrm{a}, \mathrm{c}, \mathrm{d}}$ & $1.54 \pm 0.13^{\mathrm{a}, \mathrm{d}}$ & $29.7 \pm 4.62^{\mathrm{a}, \mathrm{c}}$ & $123 \pm 17.5$ & $15.2 \pm 5.58^{\mathrm{a}}$ \\
\hline ANOVA & $\mathrm{p}<0.0005$ & $\mathrm{p}<0.05$ & $\mathrm{p}<0.0001$ & $\mathrm{p}<0.0005$ & $\mathrm{p}<0.0001$ & n.s. & $\mathrm{p}<0.05$ \\
\hline
\end{tabular}

${ }^{\mathrm{a}} \mathrm{p}<0.05$ vs. untreated sham; ${ }^{\mathrm{b}} \mathrm{p}<0.05$ vs. SNX+anemia; ${ }^{\mathrm{c}} \mathrm{p}<0.05$ vs. untreated SNX; ${ }^{\mathrm{d}} \mathrm{p}<0.05$ vs. sham+anemia. LVEDP $=$ Left ventricular end-diastolic pressure.

Table 2. Echocardiographic findings

\begin{tabular}{|c|c|c|c|c|c|c|c|}
\hline Group & $\begin{array}{l}\text { Systolic } \\
\text { IVS, cm }\end{array}$ & $\begin{array}{l}\text { Diastolic } \\
\text { IVS, } \mathrm{cm}\end{array}$ & $\begin{array}{l}\text { Diastolic } \\
\text { IVS, } \mathrm{cm} / \mathrm{kg}\end{array}$ & $\begin{array}{l}\text { LV Vol } \\
\text { diast., } \mathrm{cm}^{3}\end{array}$ & $\begin{array}{l}\mathrm{LV} \text { Vol } \\
\text { diast., } \mathrm{cm}^{3} / \mathrm{kg}\end{array}$ & $\mathrm{EF}, \%$ & FS \\
\hline Untreated sham $(\mathrm{n}=4)$ & $0.27 \pm 0.02$ & $0.16 \pm 0.01$ & $0.35 \pm 0.01$ & $1.13 \pm 0.33$ & $2.43 \pm 0.66$ & $78.0 \pm 5.2$ & $42.1 \pm 4.4$ \\
\hline Sham+anemia $(\mathrm{n}=4)$ & $0.28 \pm 0.04$ & $0.17 \pm 0.01$ & $0.43 \pm 0.05^{\mathrm{a}}$ & $1.15 \pm 0.33$ & $2.98 \pm 1.11$ & $76.4 \pm 4.0$ & $43.3 \pm 8.8$ \\
\hline Untreated SNX $(\mathrm{n}=4)$ & $0.26 \pm 0.02$ & $0.16 \pm 0.01$ & $0.40 \pm 0.03^{\mathrm{a}}$ & $1.10 \pm 0.27$ & $2.75 \pm 0.66$ & $77.5 \pm 1.3$ & $41.2 \pm 1.3$ \\
\hline SNX+anemia $(\mathrm{n}=3)$ & $0.25 \pm 0.02$ & $0.15 \pm 0.02$ & $0.41 \pm 0.04^{\mathrm{a}}$ & $1.28 \pm 0.12$ & $3.39 \pm 0.24$ & $74.3 \pm 0.6$ & $39.2 \pm 0.3$ \\
\hline ANOVA & n.s. & n.s. & $\mathrm{p}<0.05$ & n.s. & n.s. & n.s. & n.s. \\
\hline
\end{tabular}

IVS = Interventricular septum; LV Vol = left ventricular volume; EF = ejection fraction; FS = fractional shortening; ${ }^{\mathrm{a}} \mathrm{p}<0.05 \mathrm{vs.}$ untreated sham.

ing that the combination of anemia and renal failure leads to more marked LVH than either condition alone (tables 1 and 2 ; fig. 1 ).

Systolic Blood Pressure and Heart Rate Values

At the end of the study, intra-arterially measured systolic blood pressure was comparable in all four groups, with the highest value in the SNX+anemia group (table 1). In parallel, the heart rate was highest in SNX+anemia $(395 \pm 22.9)$ and lowest in sham (313 \pm 54.9$)$, but the difference between the groups was not statistically significant.

\section{Left Ventricular End-Diastolic Pressure}

At the end of the study, LVEDP was significantly higher in both SNX than in sham with no additional effect of anemia. The marked elevation of mean LVEDP in SNX animals approached a level reported for animals with experimental congestive heart failure and was statistically significant compared to controls [19]. Of note, anemia alone led to a less pronounced increase (table 1).
Echocardiography (table 2)

Echocardiography demonstrated similar thickness of the interventricular septum between all groups both in systole and diastole. If adjusted for the relevant differences in body weight, a significant difference between untreated controls and all other groups emerged. Left ventricular diastolic volume was not statistically significant between the four groups. Ejection fraction and fractional shortening differed only marginally, with highest values in controls and lowest in the SNX+anemia group.

\section{Cardiac Capillary Length and Volume Density and Intercapillary Distance}

Volume density of intramyocardial capillaries was significantly lower in untreated SNX than in SNX+anemia (9.25 $\pm 2.84 \%)$, sham+anemia (10.2 $\pm 3.93 \%)$ and untreated sham (11.5 $\pm 2.73 \%)$. Capillary length density, i.e. the total length of all intramyocardial capillaries per volume myocardium, was highest in untreated sham $(5,216$ $\left.\pm 626 \mathrm{~mm} / \mathrm{mm}^{3}\right)$ and lowest in untreated SNX $(3,883 \pm$ 
Fig. 2. Representative morphology of the heart in sham (a), sham+anemia (b), SNX (c) and SNX+anemia (d). Note slight wall thickening of intramyocardial arterioles in sham+anemia (b), which is much more pronounced in SNX (c) and SNX+anemia (d). Semi-thin sections. $\times 40$.
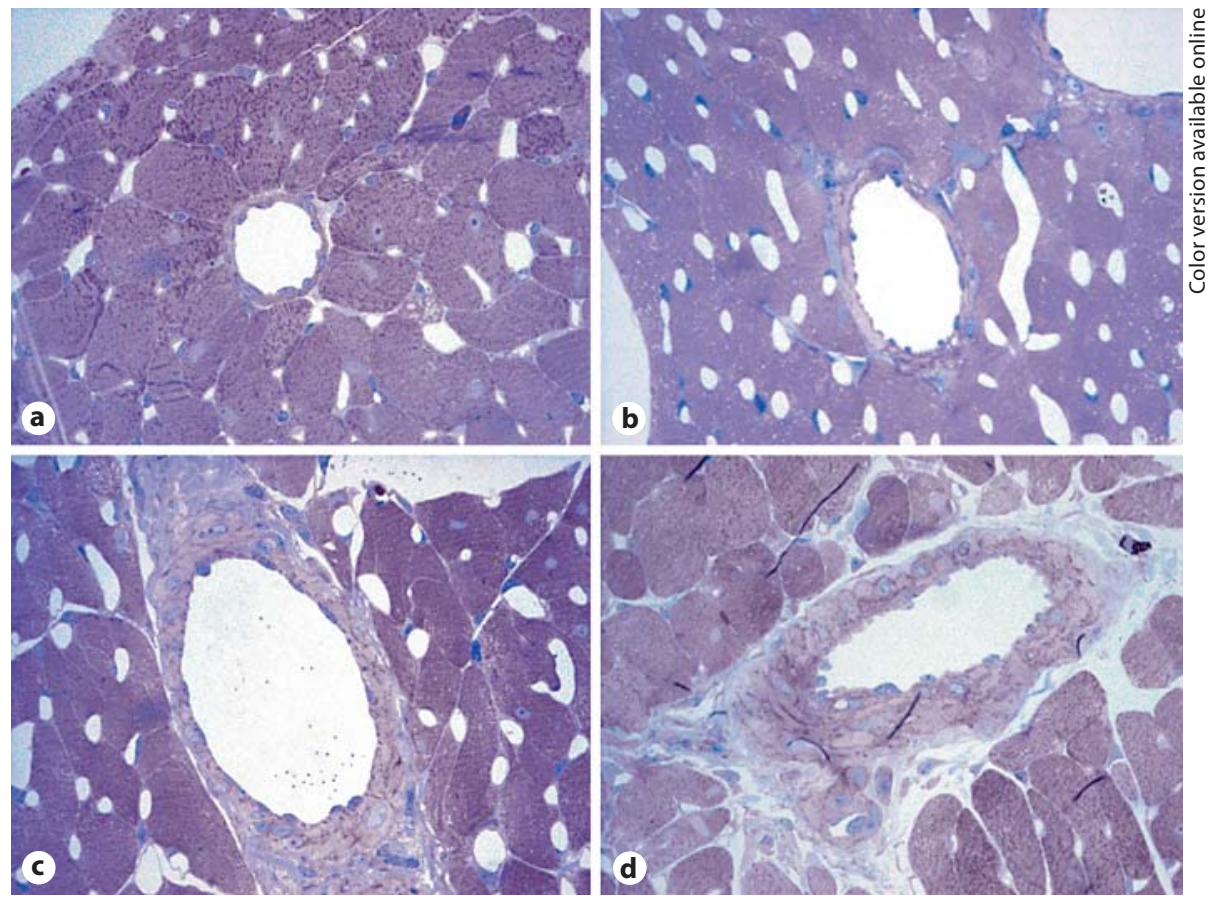

Table 3. Changes of myocardial nonvascular tissue

\begin{tabular}{llll}
\hline Group & \multicolumn{2}{l}{ Volume density, $\%$} & \\
\cline { 2 - 4 } & $\begin{array}{l}\text { interstitial } \\
\text { matrix }\end{array}$ & $\begin{array}{l}\text { interstitial } \\
\text { fibroblasts }\end{array}$ & $\begin{array}{l}\text { total nonvascular } \\
\text { interstitium }\end{array}$ \\
\hline Untreated sham $(\mathrm{n}=4)$ & $1.5 \pm 0.26$ & $0.27 \pm 0.11$ & $1.77 \pm 0.18$ \\
Sham+anemia $(\mathrm{n}=4)$ & $1.90 \pm 0.51$ & $0.31 \pm 0.11$ & $2.21 \pm 0.52$ \\
Untreated SNX $(\mathrm{n}=4)$ & $2.34 \pm 0.76$ & $0.64 \pm 0.21^{\mathrm{a}-\mathrm{c}}$ & $2.98 \pm 0.86$ \\
SNX+anemia $(\mathrm{n}=3)$ & $2.7 \pm 1.01$ & $0.38 \pm 0.08^{\mathrm{d}}$ & $3.08 \pm 0.96$ \\
ANOVA & n.s. & $\mathrm{p}<0.05$ & n.s. $(\mathrm{p}=0.06)$ \\
\hline
\end{tabular}

${ }^{\mathrm{a}} \mathrm{p}<0.05$ vs. untreated sham; ${ }^{\mathrm{b}} \mathrm{p}<0.05$ vs. SNX+anemia; ${ }^{\mathrm{c}} \mathrm{p}<0.05$ vs. sham + anemia; ${ }^{\mathrm{d}} \mathrm{p}<0.05$ vs. untreated SNX.

$\left.1,461 \mathrm{~mm} / \mathrm{mm}^{3}\right)$. The values in SNX+anemia $(4,520 \pm$ $\left.909 \mathrm{~mm} / \mathrm{mm}^{3}\right)$ and sham+anemia $(4,833 \pm 1,065 \mathrm{~mm} /$ $\mathrm{mm}^{3}$ ) were intermediate. Although capillarization was nearly $40 \%$ lower in untreated SNX than in untreated sham, the difference was not statistically significant, and this was due to the high standard deviation in the few animals.

\section{Interstitial Nonvascular Tissue}

Volume density of interstitial fibroblasts (in \%) was significantly higher in untreated SNX than in the other groups. Volume density of intercellular matrix was higher in both SNX groups compared to sham, but the differences were not statistically significant. When both parameters were combined, the volume density of total nonvascular interstitial tissue, i.e. the percentage of interstitial fibroblasts and interstitial matrix per volume myocardium, was markedly higher in both SNX groups than in sham, but the difference marginally failed to be significant $(p=0.06)$. There was no significant difference between sham or SNX animals with or without anemia, respectively (table 3 ; fig. 2). 
Table 4. Changes of intramyocardial arterioles

\begin{tabular}{|c|c|c|c|}
\hline \multirow[t]{2}{*}{ Group } & \multicolumn{3}{|c|}{ Intramyocardial arterioles } \\
\hline & $\begin{array}{l}\text { wall thickness } \\
\mu \mathrm{m}\end{array}$ & $\begin{array}{l}\text { wall:lumen ratio } \\
\mu \mathrm{m} / \mu \mathrm{m} \times 10^{-2}\end{array}$ & $\begin{array}{l}\text { media area:lumen area } \\
\mu \mathrm{m}^{2} / \mu \mathrm{m}^{2} \times 10^{-2}\end{array}$ \\
\hline Untreated sham $(\mathrm{n}=4)$ & $2.92 \pm 0.39$ & $6.69 \pm 2.98$ & $32.6 \pm 8.45$ \\
\hline Sham+anemia $(\mathrm{n}=4)$ & $4.22 \pm 0.88^{\mathrm{a}}$ & $12.5 \pm 4.68$ & $44.1 \pm 15.55$ \\
\hline Untreated SNX $(\mathrm{n}=4)$ & $5.32 \pm 1.17^{\mathrm{a}}$ & $18.3 \pm 1.15^{\mathrm{a}}$ & $60.6 \pm 9.41^{\mathrm{a}}$ \\
\hline SNX+anemia $(\mathrm{n}=3)$ & $5.05 \pm 0.76^{\mathrm{a}}$ & $17.2 \pm 5.0^{\mathrm{a}}$ & $72.6 \pm 26.4^{\mathrm{a}}$ \\
\hline ANOVA & $\mathrm{p}<0.01$ & $\mathrm{p}<0.005$ & $\mathrm{p}<0.05$ \\
\hline
\end{tabular}

${ }^{\mathrm{a}} \mathrm{p}<0.05$ vs. untreated sham.

\section{Intramyocardial Arterioles (table 4)}

In all eight sections per animal, all intramyocardial arterioles with lumen diameters between 20 and $120 \mu \mathrm{m}$ were measured. The mean number of arteries per group varied from 96 in sham to 58 in SNX. The mean number of intramyocardial arteries per animal ranged from 11 to 31. The cumulative frequencies of arteries were not different between the groups excluding a sampling error. This was also confirmed by the fact that mean lumen diameter was not significantly different between the groups. In contrast, wall thickness, wall:lumen ratio and media area: lumen area were significantly higher in both SNX groups than in untreated sham. Of note, arteriolar wall thickness was also significantly increased when anemia was induced in sham animals, indicating a hypertrophic effect of anemia per se on vascular smooth muscle cells.

\section{Discussion}

Cardiovascular complications are a major clinical problem in patients with CRF. Specific structural changes of the heart and the extracardiac vessels have been demonstrated in patients as well as in experimental models of CRF [14, 20,21]. Anemia is another hallmark of renal failure, and the debate on how to correct anemia in the era of erythropoietin (EPO) is ongoing [4, 22]. Among others, anemia was always suspected to account for some of the cardiovascular structural and functional alterations in renal failure, and it was speculated that the effects of anemia and uremia may potentiate each other. Up to now, however, long-term data that synchronously address both the separate and the concerted effects of anemia and uremia on cardiac function and in particular detailed quantitative studies of cardiac morphology under these conditions are missing or scarce.
The salient feature of the present experimental study on cardiovascular effects of anemia, uremia and a combination of both is the documentation (a) that anemia per se with a hematocrit of $30 \%$ and moderate CRF induced a comparable $\mathrm{LVH}$ of about $15 \%$ and (b) that the combination of anemia and uremia led to an even higher increase in LVH of about $37 \%$ compared to control animals. In addition, anemia per se increased LVEDP and also wall thickness of intramyocardial arteries in control animals. Both values were again higher in uremia and in uremia+anemia. The increase in LVEDP in the presence of normal ejection fraction and systolic function indices is indicative of diastolic dysfunction - a finding that is compatible with the observed changes in volume density of the cardiac nonvascular interstitium.

Of note, anemia per se induced marked thickening of intramyocardial arteries, but had lesser effect on interstitial fibrosis or myocardial capillarization, respectively. Thus, anemia has the potential to aggravate LVH in CRF, but leads to only little change in the histomorphology of the heart, particularly in intramyocardial arteries.

Though limited by the small sample size, we did not detect any statistically significant difference in heart rate or blood pressure. In line with published evidence, anemia and uremia per se seem to be major causal factors of the described effects that act largely independently of either blood pressure or heart rate [23].

Furthermore, no accelerated progression of kidney disease, as measured by S-creatinine, was noted by anemia. We have to acknowledge, however, that the rat model of subtotal nephrectomy leads to mild to moderate CRF which per se is accompanied by mild anemia [14].

Our findings extend data from the literature investigating the cardiovascular effects of anemia in various experimental models using different experimental settings [2326]. As early as 1964, Poupa et al. [25] found that diet-in- 
duced anemia of 100 days duration after weaning led to growth retardation and cardiac hypertrophy. Olivetti et al. [24] demonstrated a 50\% increase in heart weight after hypochromic microcytic anemia induced by an iron- and copper-deficient diet for 7 weeks with a greater enlargement in right (65\%) than in left ventricular mass (47\%). Of note, LVH was accompanied by a comparable lengthening of the capillary network indicating capillary proliferation in parallel with myocyte hypertrophy in order to prevent the myocardium from ischemic injury. Recently, using similar stereological techniques, Rakusan et al. [23] showed that induction of chronic iron-deficient anemia of 6 weeks' duration in young rats resulted in increased LVEDP, decreased functional reserve as well as LVH of about 25\%. As in the study of Olivetti et al. [24] capillary and arteriolar densities remained unchanged, indicating angiogenesis in this experimental situation of LVH. In SHR rats with genetically determined hypertension, Olivetti et al. [26] found that the superimposition of anemia resulted in a $43 \%$ expansion in left ventricular weight, with a decrease in left ventricular peak systolic pressure and the rate of rise in left ventricular pressure $(+\mathrm{dP} / \mathrm{dt})$, and an increase in LVEDP. Wall thickening and a preservation of chamber volume already occurred in SHR rats, while SHR rats with anemia showed a degree of ventricular dilatation which exceeded the extent of wall thickening.

The general problem in LVH is that due to hypertrophy of cardiomyocytes and a concomitant increase in capillary-myocyte distance, a mismatch between oxygen supply and consumption occurs. This situation is clearly aggravated under the condition of CRF by a capillarization deficit in the heart, the kidney and some peripheral tissues $[12,20,27-30]$. In the present study, however, there is only a tendency to higher capillary density in anemia, possibly indicating that the principal mechanism of capillary adaptation appears intact.

In a previous study, we investigated the effect of recombinant human erythropoietin on cardiovascular alterations in our model of subtotal nephrectomy [14]. We found no effect of EPO treatment on reduced capillary length density, interstitial fibrosis or thickening of intramyocardial arteries in SNX rats. Thus, this study had clearly shown that lack of EPO does not cause, or contribute to, the deficit of capillary growth in the hypertrophied left ventricle of rats with renal failure and that a rise in hematocrit is not necessarily accompanied by beneficial effects on alterations of cardiovascular structure in experimental renal failure.

Using gene expression analysis and EPO (48 U/kg/ week) or hydralazine treatment, respectively, Mak et al.
[31] investigated the effects of anemia and hypertension in uremic LVH. They found that treatment of anemia with EPO improved uremic LVH, whereas treatment of hypertension with hydralazine did not. With respect to gene expression, the authors concluded that uremic LVH is distinct from pressure-overload LVH.

In interpreting the results of the present study, it is important to consider several methodological problems. In contrast to previous studies that induced anemia for a substantially shorter period of time, in very young animals or by methods with poorly defined systemic effects (like restriction of nutrients or thyroid hormone deficiency [32]), we aimed to investigate the consequences of anemia in a tightly controlled chronic model. Our approach included rather mature animals, a relatively long observational period of 16 weeks and a laborious but precise induction of anemia by frequent and defined phlebotomies. In turn, this invasive long-term approach contributed to a high dropout rate in both anemia groups. The animal number per group and thus the statistical power of some of the data is limited. Consequently, despite the highly significant differences of some parameters, our results have to be interpreted with great caution.

In order to avoid potential artifacts from the anisotropy of the myocardium, i.e. the distribution of structures follows preferential orientations, the orientator technique [18] was used to obtain random samples of the myocardium, thus preventing any systematic error of spatial preference.

Unfortunately, we do not have any data on a possible activation of the sympathetic nervous system which has been shown to occur in anemia [33]. It is well known, however, that CRF is a state of sympathetic activation per se $[34,35]$.

Concerning the clinical perspective of the above data, we have to emphasize that anemia is definitely not a benign condition and can obviously induce cardiovascular alterations. In combination with CRF, however, there are possibly, but not necessarily, additive effects, and therefore correction may not always lead to cardiovascular benefits.

\section{Acknowledgments}

Parts of the study were sponsored by a grant from Johnson \& Johnson and by the IZKF Erlangen (A11). The authors thank Monika Klewer, Stefan Söllner, Astrid Schiche and Miriam Reutelshöfer for expert technical assistance. 


\section{References}

$\checkmark 1$ Silverberg DS, Wexler D, Iaina A, Schwartz $\mathrm{D}$ : The interaction between heart failure and other heart diseases, renal failure, and anemia. Semin Nephrol 2006;26:296-306.

-2 Silverberg DS, Wexler D, Blum M, Wollman Y, Schwartz D, Sheps D, Keren G, Iaina A: The interaction between heart failure, renal failure and anemia - the cardio-renal anemia syndrome. Blood Purif 2004;22:277284.

$\checkmark 3$ Regidor DL, Kopple JD, Kovesdy CP, Kilpatrick RD, McAllister CJ, Aronovitz J, Greenland S, Kalantar-Zadeh K: Associations between changes in hemoglobin and administered erythropoiesis-stimulating agent and survival in hemodialysis patients. J Am Soc Nephrol 2006;17:1181-1191.

4 Drueke TB, Locatelli F, Clyne N, Eckardt KU, Macdougall IC, Tsakiris D, Burger HU, Scherhag A: Normalization of hemoglobin level in patients with chronic kidney disease and anemia. N Engl J Med 2006;355:20712084.

5 Silverberg DS, Wexler D, Blum M, Tchebiner JZ, Sheps D, Keren G, Schwartz D, Baruch R, Yachnin T, Shaked M, Schwartz I, Steinbruch S, Iaina A: The effect of correction of anaemia in diabetics and non-diabetics with severe resistant congestive heart failure and chronic renal failure by subcutaneous erythropoietin and intravenous iron. Nephrol Dial Transplant 2003;18:141-146.

-6 Sarnak MJ, Tighiouart H, Manjunath G, MacLeod B, Griffith J, Salem D, Levey AS: Anemia as a risk factor for cardiovascular disease in The Atherosclerosis Risk in Communities (ARIC) study. J Am Coll Cardiol 2002;40:27-33.

$\checkmark 7$ Weiskopf RB, Viele MK, Feiner J, Kelley S, Lieberman J, Noorani M, Leung JM, Fisher DM, Murray WR, Toy P, Moore MA: Human cardiovascular and metabolic response to acute, severe isovolemic anemia. JAMA 1998;279:217-221.

>8 Parfrey PS, Foley RN, Harnett JD, Kent GM, Murray DC, Barre PE: Outcome and risk factors for left ventricular disorders in chronic uraemia. Nephrol Dial Transplant 1996;11: 1277-1285.

-9 Silberberg J, Racine N, Barre P, Sniderman $\mathrm{AD}$ : Regression of left ventricular hypertrophy in dialysis patients following correction of anemia with recombinant human erythropoietin. Can J Cardiol 1990;6:1-4.

$\checkmark 10$ Amann K, Wolf B, Nichols C, Tornig J, Schwarz U, Zeier M, Mall G, Ritz E: Aortic changes in experimental renal failure: hyperplasia or hypertrophy of smooth muscle cells? Hypertension 1997;29:770-775.

- 11 Tornig J, Amann K, Ritz E, Nichols C, Zeier M, Mall G: Arteriolar wall thickening, capillary rarefaction and interstitial fibrosis in the heart of rats with renal failure: the effects of ramipril, nifedipine and moxonidine. J Am Soc Nephrol 1996;7:667-675.
12 Amann K, Wiest G, Zimmer G, Gretz N, Ritz E, Mall G: Reduced capillary density in the myocardium of uremic rats - a stereological study. Kidney Int 1992;42:1079-1085.

13 Amann K, Ritz C, Adamczak M, Ritz E: Why is coronary heart disease of uraemic patients so frequent and so devastating? Nephrol Dial Transplant 2003;18:631-640.

14 Amann K, Buzello M, Simonaviciene A, Miltenberger-Miltenyi G, Koch A, Nabokov A, Gross ML, Gless B, Mall G, Ritz E: Capillary/myocyte mismatch in the heart in renal failure - a role for erythropoietin? Nephrol Dial Transplant 2000;15:964-969.

15 Amann K, Hofstetter J, Campean V, Koch A, Gross ML, Veelken R, Ritz E: Nonhypotensive dose of beta-adrenergic blocker ameliorates capillary deficits in the hearts of rats with moderate renal failure. Virchows Arch 2006;449:207-214.

16 Diehl KH, Hull R, Morton D, Pfister R, Rabemampianina Y, Smith D, Vidal JM, van de Vorstenbosch C: A good practice guide to the administration of substances and removal of blood, including routes and volumes. J Appl Toxicol 2001;21:15-23.

17 Philipp S, Jurgensen JS, Fielitz J, Bernhardt WM, Weidemann A, Schiche A, Pilz B, Dietz R, Regitz-Zagrosek V, Eckardt KU, Willenbrock R: Stabilization of hypoxia inducible factor rather than modulation of collagen metabolism improves cardiac function after acute myocardial infarction in rats. Eur J Heart Fail 2006;8:347-354.

18 Mattfeldt T, Mall G, Gharehbaghi H, Moller P: Estimation of surface area and length with the orientator. J Microsc 1990;159:301-317.

-19 Nielsen S, Terris J, Andersen D, Ecelbarger C, Frokiaer J, Jonassen T, Marples D, Knepper MA, Petersen JS: Congestive heart failure in rats is associated with increased expression and targeting of aquaporin-2 water channel in collecting duct. Proc Natl Acad Sci USA 1997;94:5450-5455.

20 Amann K, Breitbach M, Ritz E, Mall G: Myocyte/capillary mismatch in the heart of uremic patients. J Am Soc Nephrol 1998;9:1018 1022.

21 Amann K, Ritz E: The heart in renal failure: morphological changes of the myocardium - new insights. J Clin Basic Cardiol 2001; 4:109-113.

22 Eckardt KU: Managing a fateful alliance: anaemia and cardiovascular outcomes. Nephrol Dial Transplant 2005;20(suppl 6): vi16-vi20.

23 Rakusan K, Cicutti N, Kolar F: Effect of anemia on cardiac function, microvascular structure, and capillary hematocrit in rat hearts. Am J Physiol Heart Circ Physiol 2001; 280:H1407-H1414.
24 Olivetti G, Lagrasta C, Quaini F, Ricci R, Moccia G, Capasso JM, Anversa P: Capillary growth in anemia-induced ventricular wall remodeling in the rat heart. Circ Res 1989;65: 1182-1192.

25 Poupa O, Korecky B, Krofta K, Rakusan K, Prochazka J: The effect of anaemia during the early postnatal period on vascularisation of the myocardium and its resistance to anoxia. Physiol Bohemoslov 1964;13:281-287.

26 Olivetti G, Quaini F, Lagrasta C, Ricci R, Tosini P, Capasso JM, Anversa P: Effects of genetic hypertension and nutritional anaemia on ventricular remodelling and myocardial damage in rats. Cardiovasc Res 1993;27: 1316-1325.

27 Amann K, Ritz E: Microvascular disease the Cinderella of uraemic heart disease. Nephrol Dial Transplant 2000;15:14931503.

28 Kang DH, Hughes J, Mazzali M, Schreiner GF, Johnson RJ: Impaired angiogenesis in the remnant kidney model. II. Vascular endothelial growth factor administration reduces renal fibrosis and stabilizes renal function. J Am Soc Nephrol 2001;12:1448-1457.

29 Jacobi J, Porst M, Cordasic N, Namer B, Schmieder RE, Eckardt KU, Hilgers KF: Subtotal nephrectomy impairs ischemiainduced angiogenesis and hindlimb re-perfusion in rats. Kidney Int 2006;69:20132021.

30 Gilchrest BA, Rowe JW, Mihm MC Jr: Clinical and histological skin changes in chronic renal failure: evidence for a dialysis-resistant, transplant-responsive microangiopathy. Lancet 1980;2:1271-1275.

-31 Mak RH, Chang SL, Draksharapu A, Pak YK: Gene expression in uremic left ventricular hypertrophy: effects of hypertension and anemia. Exp Mol Med 2004;36:251-258.

32 Penney DG, Barthel BG: Effects of thyroid and growth hormone deficiency, and food restriction on heart mass, with and without added stress (carboxyhemoglobinemia). Can J Physiol Pharmacol 1985;63:642-648.

$>33$ Metivier F, Marchais SJ, Guerin AP, Pannier B, London GM: Pathophysiology of anaemia: focus on the heart and blood vessels. Nephrol Dial Transplant 2000;15(suppl 3):14-18.

>34 Neumann J, Ligtenberg G, Klein II, Koomans HA, Blankestijn PJ: Sympathetic hyperactivity in chronic kidney disease: pathogenesis, clinical relevance, and treatment. Kidney Int 2004;65:1568-1576.

$>35$ Joles JA, Koomans HA: Causes and consequences of increased sympathetic activity in renal disease. Hypertension 2004;43:699706 . 